Published in final edited form as:

JAMA Pediatr. 2017 December 01; 171(12): 1160-1167. doi:10.1001/jamapediatrics.2017.3024.

\title{
Prenatal Air Pollution and Newborns' Predisposition to Accelerated Biological Aging
}

\author{
Dries S. Martens, MSc, Bianca Cox, PhD, and Bram G. Janssen, PhD \\ Centre for Environmental Sciences, Hasselt University, Hasselt, Belgium \\ Diana B. P. Clemente, MSc, \\ Centre for Environmental Sciences, Hasselt University, Hasselt, Belgium; Instituto de Salud \\ Global, Centre for Research in Environmental Epidemiology, Barcelona, Spain; Department of \\ Experimental and Health Sciences, Universitat Pompeu Fabra, Barcelona, Spain
}

\section{Antonio Gasparrini, PhD, England \\ Charlotte Vanpoucke, MSc, \\ Belgian Interregional Environment Agency, Brussels, Belgium \\ Wouter Lefebvre, PhD, \\ Flemish Institute for Technological Research, Mol, Belgium}

Department of Social and Environmental Health Research, London School of Hygiene \& Tropical Medicine (LSHTM), London, England; Department of Medical Statistics, LSHTM, London,

Harry A. Roels, PhD,

Centre for Environmental Sciences, Hasselt University, Hasselt, Belgium; Louvain Centre for Toxicology and Applied Pharmacology, Université catholique de Louvain, Brussels, Belgium

Michelle Plusquin, PhD, and

Centre for Environmental Sciences, Hasselt University, Hasselt, Belgium

Tim S. Nawrot, PhD

\footnotetext{
Corresponding Author: Tim S. Nawrot, PhD, Centre for Environmental Sciences, Hasselt University, Agoralaan Gebouw D, 3590 Diepenbeek, Belgium, (tim.nawrot@uhasselt.be).

Author Contributions: Mr Martens and Dr Nawrot had full access to all of the data in the study and take responsibility for the integrity of the data and the accuracy of the data analysis.

Study concept and design: Martens, Janssen, Nawrot.

Acquisition, analysis, or interpretation of data: All authors.

Drafting of the manuscript: Martens, Cox, Nawrot.

Critical revision of the manuscript for important intellectual content: Martens, Janssen, Clemente, Gasparrini, Vanpoucke, Lefebvre, Roels, Plusquin, Nawrot.

Statistical analysis: Martens, Cox, Gasparrini, Nawrot.

Obtained funding: Nawrot.

Administrative, technical, or material support: Martens, Janssen, Clemente, Lefebvre, Plusquin, Nawrot.

Study supervision: Nawrot.

Conflict of Interest Disclosures: None reported.

Additional Contributions: We thank Benoit Nemery, MD, PhD (full professor of occupational \& environmental medicine at the Department of Public Health and Primary care, Leuven University, Belgium), for his critical revision of the manuscript and Immaculata De Vivo, MPH, PhD (associate professor in the Department of Epidemiology, Harvard School of Public Health, Boston, Massachusetts), for providing help by the telomere assay. They did not receive any compensation for their contribution to this work.
} 
Centre for Environmental Sciences, Hasselt University, Hasselt, Belgium; Department of Public Health \& Primary Care, Leuven University, Leuven, Belgium

\section{Abstract}

Importance-Telomere length is a marker of biological aging that may provide a cellular memory of exposures to oxidative stress and inflammation. Telomere length at birth has been related to life expectancy. An association between prenatal air pollution exposure and telomere length at birth could provide new insights in the environmental influence on molecular longevity.

Objective-To assess the association of prenatal exposure to particulate matter (PM) with newborn telomere length as reflected by cord blood and placental telomere length.

Design, Setting, and Participants-In a prospective birth cohort (ENVIRONAGE [Environmental Influence on Ageing in Early Life]), a total of 730 mother-newborn pairs were recruited in Flanders, Belgium between February 2010 and December 2014, all with a singleton full-term birth ( 237 weeks of gestation). For statistical analysis, participants with full data on both cord blood and placental telomere lengths were included, resulting in a final study sample size of 641 .

Exposures-Maternal residential $\mathrm{PM}_{2.5}$ (particles with an aerodynamic diameter $\mathcal{2} .5 \mu \mathrm{m}$ ) exposure during pregnancy.

Main Outcomes and Measures-In the newborns, cord blood and placental tissue relative telomere length were measured. Maternal residential $\mathrm{PM}_{2.5}$ exposure during pregnancy was estimated using a high-resolution spatial-temporal interpolation method. In distributed lag models, both cord blood and placental telomere length were associated with average weekly exposures to $\mathrm{PM}_{2.5}$ during pregnancy, allowing the identification of critical sensitive exposure windows.

Results-In 641 newborns, cord blood and placental telomere length were significantly and inversely associated with $\mathrm{PM}_{2.5}$ exposure during midgestation (weeks 12-25 for cord blood and weeks 15-27 for placenta). A 5- $\mu \mathrm{g} / \mathrm{m}^{3}$ increment in $\mathrm{PM}_{2.5}$ exposure during the entire pregnancy was associated with $8.8 \%(95 \% \mathrm{CI},-14.1 \%$ to $-3.1 \%)$ shorter cord blood leukocyte telomeres and $13.2 \%$ (95\% CI, $-19.3 \%$ to $-6.7 \%$ ) shorter placental telomere length. These associations were controlled for date of delivery, gestational age, maternal body mass index, maternal age, paternal age, newborn sex, newborn ethnicity, season of delivery, parity, maternal smoking status, maternal educational level, pregnancy complications, and ambient temperature.

Conclusions and Relevance-Mothers who were exposed to higher levels of $\mathrm{PM}_{2.5}$ gave birth to newborns with shorter telomere length. The observed telomere loss in newborns by prenatal air pollution exposure indicates less buffer for postnatal influences of factors decreasing telomere length during life. Therefore, improvements in air quality may promote molecular longevity from birth onward.

Telomeres are nucleoprotein structures that cap the end of chromosomes. They can consist of several thousands of tandem-repeated TTAGGG sequences.1,2 With each cellular division, telomeres shorten. Telomere length (TL) has been associated with age-related diseases and mortality and is considered a marker of biological aging.3-8 Telomere length is also associated with environmental and lifestyle factors that influence the oxidative stress 
and inflammatory status in humans, such as smoking, 9 obesity, 10 Mediterranean diet,11 exposure to violence, 12 and life stress, 13 which underscores the vulnerability of telomeres to reactive oxygen species (ROS). In a 2015 update of the Global Burden of Disease study, ambient particulate matter (PM) was ranked as the sixth most leading risk factor influencing public health worldwide.14 Increased oxidative stress and inflammation are proposed as underlying mechanisms through which PM may influence human health.15,16 Exposure to air pollution during in utero life may have adverse effects on the fetus and neonate.17-19 The ability of PM air pollution to generate ROS has led to the hypothesis that telomere attrition is influenced by air pollution exposure.20 Occupational and population-based studies have described both positive and negative associations between different types of air pollution and TL in adults.21-27 In general, long-term exposure to PM25 and black carbon (BC) 24,26 are associated with shorter TL in adults. Because TL is highly variable at birth, 28,29 potential determinants, such as newborn sex,28 paternal age, 28 maternal prepregnancy body mass index (BMI),20 maternal stress,30 maternal educational level,31 maternal smoking during pregnancy,32 and maternal residential proximity to a major road,33 have recently been explored for explaining this phenomenon. In this regard, we hypothesized that exposure to PM air pollution during pregnancy may contribute to telomere setting at birth. Because in utero life is believed to be a critical time window in the early programming of diseases later in life, 34 unravelling the connection between prenatal air pollution exposure and TL at birth may help to gain new insights in the causes of diseases linked with telomere biological characteristics. In this study, we assessed the association between prenatal exposure to $\mathrm{PM}_{2.5}$ (particulate matter with an aerodynamic diameter $\_.5 \mu \mathrm{m}$ ) and TL at birth.

\section{Methods}

\section{Study Population}

From the ongoing population-based prospective Environmental Influence on Ageing in Early Life (ENVIRONAGE) birth cohort study, 730 mothers with a singleton full-term birth ( 237 weeks of gestation) were selected.35 These mother-newborn pairs were recruited between February 2010 and December 2014 from noon on Fridays to 7 Am Mondays. The study protocol was approved by the ethical committees of Hasselt University and East-Limburg Hospital in Genk, Belgium, and has been carried out according to the Helsinki declaration. 36 The mother's ability to fill out questionnaires in Dutch was a criterion for selection. Owing to missing exposure data $(\mathrm{n}=10)$, the unavailability of DNA or bad DNA quality for cord blood $(n=12)$ and placenta $(n=51)$, and too high a variability of TL measurement between triplicates of cord blood $(n=10)$ or placental tissue $(n=9)$, we obtained cord blood TL samples from 698 mother-newborn pairs and placental TL samples from 660. For statistical analysis, we used participants with full data on both cord blood and placental TLs, resulting in a final study sample size of 641 .

\section{Mean Relative TL Measurement}

DNA was extracted from cord blood buffy coat and placental tissue (details on sample collection are provided in eMethods 1 in the Supplement). Mean relative TL was determined in triplicate with a previously37 described modified quantitative, real-time polymerase chain 
reaction (qPCR) protocol.38 For cord blood, the triplicates of the telomere runs showed a coefficient of variation $(\mathrm{CV})$ of $0.68 \%$, those of single-copy gene runs a CV of $0.41 \%$, and those of $\mathrm{T} / \mathrm{S}$ ratios a $\mathrm{CV}$ of $6.4 \%$. For placental telomeres, the triplicates of the telomere runs showed a CV of $0.70 \%$, those of the single-copy gene runs a CV of $0.45 \%$, and those of $\mathrm{T} / \mathrm{S}$ ratios a $\mathrm{CV}$ of $6.9 \%$.

\section{Exposure Assessment}

Based on the mother's residential address, daily mean $\mathrm{PM}_{2.5}$ concentrations (in micrograms per cubic meter) were estimated using a high-resolution spatial-temporal interpolation method (kriging)39 in combination with a dispersion model.40,41 This interpolation method uses hourly measured $\mathrm{PM}_{2.5}$ pollution data collected at the official fixed-site monitoring stations $(n=34)$ and land-cover data obtained from satellite images.42 The model chain provides daily $\mathrm{PM}_{2.5}$ values on a dense, irregular receptor grid by using data both from the Belgian telemetric air-quality network and emissions from point sources and line sources. In the Flemish region of Belgium, more than $80 \%\left(R^{2}=0.8\right)$ of the temporal and spatial variability was explained by this interpolation tool.43 For each week of pregnancy from the date of conception onward, a mean $\mathrm{PM}_{2.5}$ concentration was calculated using daily mean $\mathrm{PM}_{2.5}$ concentrations at the mother's residence. In case the mother had a gestation of less than 40 weeks, exposure was set at zero for the weeks after giving birth. The number of mothers who changed address during pregnancy (69 of 641 [10.7\%]) was taken into account when calculating the weekly exposures. Weekly mean ambient temperatures were calculated based on the daily mean temperatures in degrees Celsius provided by the Royal Meteorological Institute, Brussels, Belgium.

\section{General Study Procedures}

At the first antenatal visit (weeks 7-9 of pregnancy), maternal BMI was determined by calculating weight in kilograms divided by height in meters squared. The date of conception was estimated on the basis of the first day of the mother's last menstrual period combined with the first ultrasonographic examination. After delivery, mothers provided written informed consent and completed the study questionnaires in the post-delivery ward. We collected detailed information about the mothers, fathers, and newborns from questionnaires and medical records. Parity was categorized in mothers having their first newborn, having their second newborn, or having their third or more newborn. Maternal educational level was coded "low" when mothers did not obtain any diploma, "middle" when they obtained a high school diploma, and "high" when they obtained a college or university degree. Maternal smoking status was categorized as "never smoker," "former smoker" when the mother had quit smoking before pregnancy, and "smoker" when smoking continued during pregnancy. Newborns were classified as white European when 2 or more grandparents were Europeans, and non-European when at least 3 grandparents were of non-European origin. The presence of pregnancy complications was defined as the experience by the mother of 1 or more of the following conditions during pregnancy: gestational diabetes, hypertension, infectious disease, preeclampsia, vaginal bleeding, and hyperthyroidism or hypothyroidism. Perinatal measures, such as birth date, newborn sex, birth weight, and Apgar score were obtained after birth. 


\section{Statistical Analysis}

We used distributed lag models (DLMs) to model the association between $\log _{10}$-transformed $\mathrm{TL}$ and mean weekly $\mathrm{PM}_{2.5}$ exposures during gestational weeks 1 to 40 . A distributed lag (nonlinear) model (DLNM) is defined through a "cross-basis" function, which allows the simultaneous estimation of an (nonlinear) exposure-response association and nonlinear effects across lags, the latter termed lag-response association.44The exposure-response function was assumed to be linear and the lag structure was modeled using a natural cubic spline with $5 d f$, setting the knots at equally spaced values in the original lag scale (1-40 weeks). The number of knots was chosen based on the Akaike information criterion (AIC). $45 \mathrm{We}$ also included a cross-basis for weekly mean temperature in the model. We used a natural cubic spline with $4 d f$ for the temperature-TL function and a natural cubic spline with $5 d f$ for the lag structure (with knots at equally spaced values in the original lag scale). In addition, we accounted for a priori selected covariates that include known determinants of newborn or adult TL and variables with a potential link with $\mathrm{PM}_{2.5}$ and TL, such as date of delivery, gestational age, maternal BMI, maternal age, paternal age, newborn's sex, ethnicity, season of delivery, parity, maternal smoking status, maternal educational level, and pregnancy complications. We calculated cumulative effect estimates for the 3 trimesters of pregnancy (weeks 1-13, weeks 14-26, and weeks 27-40) and the overall (40-week) cumulative estimate. Final estimates are presented as percentage change (with 95\% CI) in $\mathrm{TL}$ for a $5-\mu \mathrm{g} / \mathrm{m}^{3}$ increment in $\mathrm{PM}_{2.5}$. Details on secondary analyses (ie, average exposure models, effect modification by sex, and nonlinear dose-response models) and sensitivity analyses are provided in eMethods 2 in the Supplement. All analyses were performed with the statistical software R, version 3.3.2 (R Project for Statistical Computing) using the dlnm package.46

\section{Results}

\section{Characteristics of the Study Population}

Table 1 describes the general characteristics of the study population $(n=641)$. The newborns, among them 318 girls (49.6\%), had a mean (SD) gestational age of 39.4 (1.0) weeks and a mean (SD) birth weight of 3451 (428) g. Most ( $\mathrm{n}=567,88.5 \%)$ of the newborns were Europeans of white ethnicity. The mean relative TL of newborns ranged from 0.51 to 1.75 in cord blood and from 0.52 to 1.89 for placental tissue. Associations of covariates with newborn TL are reported in eTable 1 in the Supplement. Mean (SD) maternal age was 29.1 (4.6) years, and mean (SD) maternal BMI was 24.3 (4.5). Among the mothers, 351 (54.8\%) were primiparous and 224 (34.9\%) secundiparous. Mean weekly $\mathrm{PM}_{2.5}$ exposure was $13.4 \mu \mathrm{g} / \mathrm{m}^{3}$ (5th-95th percentile, $4.3-32.5 \mu \mathrm{g} / \mathrm{m}^{3}$ ). eFigure 1 in the Supplement shows the contours of the annual $\mathrm{PM}_{2.5}$ exposure in the recruitment area and the places of residence of the mothers during pregnancy.

\section{Association Between Prenatal $\mathrm{PM}_{2.5}$ Exposure and Newborn TL}

Scatterplots showing newborn TL in association with average $\mathrm{PM}_{2.5}$ exposure during the entire pregnancy are shown in eFigure 2 in the Supplement. Lag-specific (weekly) DLM estimates of the association between $\mathrm{PM}_{2.5}$ exposure during pregnancy and TL at birth are presented in the Figure. Cord blood as well as placental TL were inversely associated with 
$\mathrm{PM}_{2.5}$ exposure during midgestation: significant estimates were observed for weeks 12 to 25 in cord blood (Figure, A), with the largest negative association in week 19 and for weeks 15 to 27 in placenta (Figure, B), with the largest negative association in week 21. In contrast, a positive association between $\mathrm{PM}_{2.5}$ and cord blood $\mathrm{TL}$ was observed for exposure in weeks 32 to 34. The estimated overall (weeks 1-40) change in TL for a 5- $\mu \mathrm{g} / \mathrm{m}^{3}$ increment in $\mathrm{PM}_{2.5}$ exposure was $-8.8 \%$ (95\% CI, -14.1 to $-3.1 \%$ ) for cord blood and $-13.2 \%(95 \% \mathrm{CI}$, $-19.3 \%$ to $-6.7 \%$ ) for placenta (Table 2). Trimester-specific cumulative estimates were only significant for the second trimester: $-9.4 \%(95 \% \mathrm{CI},-13.1$ to $-5.6 \%)$ for cord blood and $-7.1 \%$ (95\% CI, $-11.6 \%$ to $-2.4 \%$ ) for placental TL.

The existence of vulnerable exposure windows (ie, the hypothesis that exposure during some weeks of pregnancy is more critical than during others) was tested by comparing the main DLM model with a DLM model assuming a constant risk during the different weeks of pregnancy (likelihood ratio test on $4 d f$ ). The main DLM model provided a better fit than the constant-risk model for cord blood (AIC, -1418.4 vs $-1407.0, P=.001$ ) but not for placental telomeres (AIC, -1173.2 vs $-1177.4, P=.46$ ). The DLM estimates are corroborated by results from the average exposure models (Table 2). For instance, the change in TL for a 5$\mu \mathrm{g} / \mathrm{m}^{3}$ increment in mean $\mathrm{PM}_{2.5}$ over the entire pregnancy was $-8.4 \%$ (95\% CI, $-13.5 \%$ to $-2.9 \%$ ) in cord blood and $-12.5 \%$ (95\% CI, $-18.4 \%$ to $-6.2 \%$ ) in placenta. We did not observe a significant modification in the association by newborn sex for cord and placental TL, and we observed a nonlinear dose-response correlation (eTables 2 and 3 in the Supplement, respectively). Assuming constant associations within the strata of lags 1 to 10,11 to 20, 21 to 30, and 31 to 40 (eFigure 3 in the Supplement), evidence for the positive association between cord blood TL and $\mathrm{PM}_{2.5}$ toward the end of pregnancy is less evident. Cumulative estimates from sensitivity analyses were similar to those from the main model (Table 3 ).

\section{Discussion}

To our knowledge, this is the first study reporting an association between $\mathrm{PM}_{2.5}$ exposure during in utero life and newborn TL. After adjustment for several covariates and potential confounders, maternal exposure to $\mathrm{PM}_{2.5}$ during pregnancy was associated with $8.8 \%$ shorter newborn cord blood and $13.2 \%$ shorter placental telomeres. By applying distributed lag models based on weekly mean $\mathrm{PM}_{2.5}$ exposures, we identified specific vulnerable periods during pregnancy. Both cord blood and placental TLs were negatively associated with $\mathrm{PM}_{2.5}$ exposure during the second trimester of pregnancy. The finding that early-life TL might forecast life span, as observed in an animal-based study of zebra finches, 47 underlines the importance of the identification of early-life TL determinants. In this regard, our results may have important health consequences later in life because a shorter TL at birth indicates less buffer capacity for postnatal influence of insults (eg, inflammation on TL). Particulate air pollution may generate ROS in a direct manner via the Fenton reaction operating at the particle surface, 48 or in an indirect manner via altered mitochondrial and nicotinamide adenine dinucleotide phosphate-oxidase functions or via inflammatory cell activation.49 Telomeres contain a great amount of guanine bases, which are vulnerable to ROS. Reactive oxygen species can induce DNA breakage, leading to increased telomere shortening in addition to cellular replication.50 The major route for airborne particles to enter the maternal organism is via inhalation. Ultrafine particles (UFPs) with a diameter less than $0.1 \mu \mathrm{m}(<100$ 
$\mathrm{nm}$ ) are able to cross the airway-blood barrier, may enter the bloodstream, and are transported to different body compartments.51-53 Whether particles can cross the placental barrier is still debated because of the rather limited evidence. Nevertheless, it has been shown recently that nanoparticles up to $240 \mathrm{~nm}$ can cross the human placental barrier and nanoparticles up to $500 \mathrm{~nm}$ may enter the fetal circulation in mice.54,55 An elevated oxidative stress status in both mother and newborn may be a potential explanation for our findings concerning $\mathrm{PM}_{2.5}$ exposure observed in the present study. Earlier studies present positive associations between air pollution exposure and placental tissue nitrosative stress56 and mitochondrial oxidative stress.57 We identified the mid-pregnancy period as a critical time window for the association of $\mathrm{PM}_{2.5}$ exposure with newborn TL. This finding is in agreement with the development of the placental barrier and maternal-fetal circulation. In the first months of pregnancy, the placental barrier remains thick with no perfusion but becomes thinner during the course of pregnancy concomitantly with increased fetal capillary development until week 10, which from then onward will facilitate an enhanced maternalfetal exchange of nutrients and waste products.58 Exposure to $\mathrm{PM}_{2.5}$ late in pregnancy (from weeks 32-34) is associated with longer telomeres in cord blood, although evidence is not conclusive. This finding may suggest the presence of a potential compensatory or overcompensatory mechanism in response to air pollution exposure in cord that is absent in placenta. Positive associations between leukocyte TL and recent exposure to air pollution have been observed previously in adults.21,22,25 An increase of telomerase activity in lymphocytes and a clonal expansion of subpopulations of lymphocytes with longer telomeres following acute exposure have been suggested as potential underlying mechanisms.21,59,60 Telomere length as assessed in the present study is a result of the combination between shortening and elongating processes prior to the telomere assessment time point. However, owing to the cumulative burden of oxidative stress during the entire pregnancy, overall newborn TL was inversely associated with prenatal exposure to air pollution. The stronger overall influence of PM on placental telomeres compared with cord blood may be due to this potential compensatory mechanism in cord blood, as we observed both positive and negative estimates for $\mathrm{PM}_{2.5}$ exposure and cord blood TL during pregnancy, whereas all estimates were negative for placental TL.

\section{Strengths and Limitations}

Our study has several strengths. First, we have a large sample size of newborns with matching cord blood and placental tissue to study TL in relation to $\mathrm{PM}_{2.5}$ air pollution exposure. Second, we used high-resolution exposure estimates based on the home addresses of the mothers, and we integrated daily concentrations to estimate weekly mean exposure during pregnancy. Compared with the more conventional approach of averaging exposures over relatively large time windows (trimesters or the entire pregnancy), the use of DLM allowed a more detailed investigation of prenatal exposure windows and enabled the identification of midpregnancy as a critical period for the association of $\mathrm{PM}_{2.5}$ with TL in cord blood as well as placenta. Third, our findings are generalizable because our study population is representative of the gestational segment of the population at large. 35

However owing to spatial variations in $\mathrm{PM}_{2.5}$ concentrations, differences in exposure may exist, as our population was recruited in a relatively small area. Our study should also be 
interpreted within the context of its potential limitations. Our results are based on exposure at the maternal residence, and potential misclassification may be present because we could not account for other exposure sources that contribute to personal exposure, such as exposure during a commute, at work, and elsewhere. However, proxies of exposure, such as residential proximity to major roads, have been shown recently to be associated with internal exposure to nanosized particles, reflecting exposure to black carbon.61 The assessment of TL at birth represents a specific snapshot in the gestational period. We were not able to evaluate telomere dynamics throughout the entire pregnancy period, and, in view of our results, the role of telomerase needs further evaluation. Parental TL may be a determinant of the initial telomere length setting of the next generation.28 Because parents exposed to $\mathrm{PM}_{2.5}$ may have shorter telomeres, the association between $\mathrm{PM}_{2.5}$ exposure and newborn TL may be mediated by parental TLs. Unfortunately, this mediation could not be evaluated in the ENVIRONAGE study because data on parental TLs were not available.

\section{Conclusions}

To our knowledge, this study is the first to report an association between prenatal exposure to $\mathrm{PM}_{2.5}$ air pollution and TL at birth, both in cord blood and placental tissue. We theorize that biological aging is associated with $\mathrm{PM}_{2.5}$ air pollution exposure, even before birth, which may underlie potential adverse health consequences later in life. This study adds to the growing body of evidence that even relatively low levels of prenatal exposure to air pollution contributes to fetal programming at the molecular level and more precisely at the level of telomere biological features. Adequate reduction of environmental fine-particle air pollution levels may promote longevity as from birth onwards and may enhance overall quality of life. Prospective follow-up studies are needed to further elucidate the outcome of $\mathrm{PM}_{2.5}$-linked telomere shortening at birth in relation to pediatric and adult health and disease later in life.

\section{Supplementary Material}

Refer to Web version on PubMed Central for supplementary material.

\section{Funding/Support}

The ENVIRONAGE birth cohort is supported by grant ERC-StG310898 from the EU Program "Ideas" and by the grant FWO, G073315N from the Flemish Scientific Fund. Dr Cox is a postdoctoral fellow of the Flemish Scientific Fund supported by grant 12Q0517N. Dr Gasparrini's contribution was supported by grant MR/M022625/1 from the Medical Research Council UK.

Role of the Funder/Sponsor: The funding sources had no role in the design and conduct of the study; collection, management, analysis, and interpretation of the data; preparation, review, or approval of the manuscript; and decision to submit the manuscript for publication.

\section{References}

1. Blackburn EH. Structure and function of telomeres. Nature. 1991; 350(6319):569-573. [PubMed: 1708110]

2. O'Sullivan RJ, Karlseder J. Telomeres: protecting chromosomes against genome instability. Nat Rev Mol Cell Biol. 2010; 11(3):171-181. [PubMed: 20125188] 
3. Benetos A, Okuda K, Lajemi M, et al. Telomere length as an indicator of biological aging: the gender effect and relation with pulse pressure and pulse wave velocity. Hypertension. 2001; 37(2 pt 2):381-385. [PubMed: 11230304]

4. Cawthon RM, Smith KR, O'Brien E, Sivatchenko A, Kerber RA. Association between telomere length in blood and mortality in people aged 60 years or older. Lancet. 2003; 361(9355):393-395. [PubMed: 12573379]

5. Demissie S, Levy D, Benjamin EJ, et al. Insulin resistance, oxidative stress, hypertension, and leukocyte telomere length in men from the Framingham Heart Study. Aging Cell. 2006; 5(4):325330. [PubMed: 16913878]

6. Haycock PC, Heydon EE, Kaptoge S, Butterworth AS, Thompson A, Willeit P. Leucocyte telomere length and risk of cardiovascular disease: systematic review and meta-analysis. BMJ. 2014; 349:g4227. [PubMed: 25006006]

7. Hunt SC, Kimura M, Hopkins PN, et al. Leukocyte telomere length and coronary artery calcium. Am J Cardiol. 2015; 116(2):214-218. [PubMed: 25960381]

8. Willeit P, Raschenberger J, Heydon EE, et al. Leucocyte telomere length and risk of type 2 diabetes mellitus: new prospective cohort study and literature-based meta-analysis. PLoS One. 2014; 9(11):e112483. [PubMed: 25390655]

9. Nawrot TS, Staessen JA, Holvoet P, et al. Telomere length and its associations with oxidized-LDL, carotid artery distensibility and smoking. Front Biosci (Elite Ed). 2010; 2:1164-1168. [PubMed: 20515788]

10. Müezzinler A, Zaineddin AK, Brenner H. Body mass index and leukocyte telomere length in adults: a systematic review and meta-analysis. Obes Rev. 2014; 15(3):192-201. [PubMed: 24165286]

11. Crous-Bou M, Fung TT, Prescott J, et al. Mediterranean diet and telomere length in Nurses' Health Study: population based cohort study. BMJ. 2014; 349:g6674. [PubMed: 25467028]

12. Theall KP, Shirtcliff EA, Dismukes AR, Wallace M, Drury SS. Association between neighborhood violence and biological stress in children. JAMA Pediatr. 2017; 171(1):53-60. [PubMed: 27842189]

13. Epel ES, Blackburn EH, Lin J, et al. Accelerated telomere shortening in response to life stress. Proc Natl Acad Sci U S A. 2004; 101(49):17312-17315. [PubMed: 15574496]

14. GBD 2015 Risk Factors Collaborators. Global, regional, and national comparative risk assessment of 79 behavioural, environmental and occupational, and metabolic risks or clusters of risks, 1990-2015: a systematic analysis for the Global Burden of Disease Study 2015. Lancet. 2016; 388(10053):1659-1724. [PubMed: 27733284]

15. Kelly FJ. Oxidative stress: its role in air pollution and adverse health effects. Occup Environ Med. 2003; 60(8):612-616. [PubMed: 12883027]

16. Schins RP, Lightbody JH, Borm PJ, Shi T, Donaldson K, Stone V. Inflammatory effects of coarse and fine particulate matter in relation to chemical and biological constituents. Toxicol Appl Pharmacol. 2004; 195(1):1-11. [PubMed: 14962500]

17. Glinianaia SV, Rankin J, Bell R, Pless-Mulloli T, Howel D. Particulate air pollution and fetal health: a systematic review of the epidemiologic evidence. Epidemiology. 2004; 15(1):36-45. [PubMed: 14712145]

18. Pedersen M, Giorgis-Allemand L, Bernard C, et al. Ambient air pollution and low birthweight: a European cohort study (ESCAPE). Lancet Respir Med. 2013; 1(9):695-704. [PubMed: 24429273]

19. Winckelmans E, Cox B, Martens E, Fierens F, Nemery B, Nawrot TS. Fetal growth and maternal exposure to particulate air pollution: more marked effects at lower exposure and modification by gestational duration. Environ Res. 2015; 140:611-618. [PubMed: 26056995]

20. Martens DS, Nawrot TS. Air pollution stress and the aging phenotype: the telomere connection. Curr Environ Health Rep. 2016; 3(3):258-269. [PubMed: 27357566]

21. Dioni L, Hoxha M, Nordio F, et al. Effects of short-term exposure to inhalable particulate matter on telomere length, telomerase expression, and telomerase methylation in steel workers. Environ Health Perspect. 2011; 119(5):622-627. [PubMed: 21169126] 
22. Hou L, Wang S, Dou C, et al. Air pollution exposure and telomere length in highly exposed subjects in Beijing, China: a repeated-measure study. Environ Int. 2012; 48:71-77. [PubMed: 22871507]

23. Hoxha M, Dioni L, Bonzini M, et al. Association between leukocyte telomere shortening and exposure to traffic pollution: a cross-sectional study on traffic officers and indoor office workers. Environ Health. 2009; 8:41. [PubMed: 19772576]

24. McCracken J, Baccarelli A, Hoxha M, et al. Annual ambient black carbon associated with shorter telomeres in elderly men: Veterans Affairs Normative Aging Study. Environ Health Perspect. 2010; 118(11):1564-1570. [PubMed: 21465749]

25. Pieters N, Janssen BG, Dewitte H, et al. Biomolecular markers within the core axis of aging and particulate air pollution exposure in the elderly: a cross-sectional study. Environ Health Perspect. 2016; 124(7):943-950. [PubMed: 26672058]

26. Ward-Caviness CK, Nwanaji-Enwerem JC, Wolf K, et al. Long-term exposure to air pollution is associated with biological aging. Oncotarget. 2016; 7(46):74510-74525. [PubMed: 27793020]

27. Wong JY, De Vivo I, Lin X, Christiani DC. Cumulative PM(2.5) exposure and telomere length in workers exposed to welding fumes. J Toxicol Environ Health A. 2014; 77(8):441-455. [PubMed: 24627998]

28. Factor-Litvak P, Susser E, Kezios K, et al. Leukocyte telomere length in newborns: implications for the role of telomeres in human disease. Pediatrics. 2016; 137(4):e20153927. [PubMed: 26969272]

29. Okuda K, Bardeguez A, Gardner JP, et al. Telomere length in the newborn. Pediatr Res. 2002; 52(3):377-381. [PubMed: 12193671]

30. Entringer S, Epel ES, Lin J, et al. Maternal psychosocial stress during pregnancy is associated with newborn leukocyte telomere length. Am J Obstet Gynecol. 2013; 208(2):134.e1-134.e7, e17. [PubMed: 23200710]

31. Wojcicki JM, Olveda R, Heyman MB, et al. Cord blood telomere length in Latino infants: relation with maternal education and infant sex. J Perinatol. 2016; 36(3):235-241. [PubMed: 26633142]

32. Salihu HM, Pradhan A, King L, et al. Impact of intrauterine tobacco exposure on fetal telomere length. Am J Obstet Gynecol. 2015; 212(2):205.e1-205.e8, e8. [PubMed: 25173189]

33. Bijnens E, Zeegers MP, Gielen M, et al. Lower placental telomere length may be attributed to maternal residential traffic exposure; a twin study. Environ Int. 2015; 79:1-7. [PubMed: 25756235]

34. Barker DJ. The fetal and infant origins of adult disease. BMJ. 1990; 301(6761):1111. [PubMed: 2252919]

35. Janssen BG, Madlhoum N, Gyselaers W, et al. Cohort Profile: The ENVIRonmental influence ON early AGEing (ENVIRONAGE): a birth cohort study. Int J Epidemiol.

36. World Medical Association. World Medical Association Declaration of Helsinki: ethical principles for medical research involving human subjects. JAMA. 2013; 310(20):2191-2194. [PubMed: 24141714]

37. Martens DS, Plusquin M, Gyselaers W, De Vivo I, Nawrot TS. Maternal pre-pregnancy body mass index and newborn telomere length. BMC Med. 2016; 14(1):148. [PubMed: 27751173]

38. Cawthon RM. Telomere length measurement by a novel monochrome multiplex quantitative PCR method. Nucleic Acids Res. 2009; 37(3):e21. [PubMed: 19129229]

39. Janssen S, Dumont G, Fierens F, Mensink C. Spatial interpolation of air pollution measurements using CORINE land cover data. Atmos Environ. 2008; 42(20):4884-4903.

40. Lefebvre W, Degrawe B, Beckx C, et al. Presentation and evaluation of an integrated model chain to respond to traffic- and health-related policy questions. Environ Model Softw. 2013; 40(0):160170.

41. Lefebvre W, Vercauteren J, Schrooten L, et al. Validation of the MIMOSA-AURORA-IFDM model chain for policy support: modeling concentrations of elemental carbon in Flanders. Atmos Environ. 2011; 45(37):6705-6713.

42. European Environmental Agency. Corine land cover. [Accessed January 30, 2017] https:// www.eea.europa.eu/publications/COR0-landcover.

43. Maiheu B, Veldeman N, Viaene P, et al. Identifying the best available large-scale concentration maps for air quality in Belgium [in Dutch]. [Accessed January 30, 2017] Published December 
2012 http://www.milieurapport.be/Upload/main/0_onderzoeksrapporten/2013/ Eindrapport_Concentratiekaarten_29_01_2013_TW.pdf.

44. Gasparrini A. Modeling exposure-lag-response associations with distributed lag non-linear models. Stat Med. 2014; 33(5):881-899. [PubMed: 24027094]

45. Gasparrini A, Armstrong B, Kenward MG. Distributed lag non-linear models. Stat Med. 2010; 29(21):2224-2234. [PubMed: 20812303]

46. Gasparrini A. Distributed lag linear and non-linear models in R: the package dlnm. J Stat Softw. 2011; 43(8):1-20.

47. Heidinger BJ, Blount JD, Boner W, Griffiths K, Metcalfe NB, Monaghan P. Telomere length in early life predicts lifespan. Proc Natl Acad Sci U S A. 2012; 109(5):1743-1748. [PubMed: 22232671]

48. Valavanidis A, Fiotakis K, Bakeas E, Vlahogianni T. Electron paramagnetic resonance study of the generation of reactive oxygen species catalysed by transition metals and quinoid redox cycling by inhalable ambient particulate matter. Redox Rep. 2005; 10(1):37-51. [PubMed: 15829110]

49. Risom L, Møller P, Loft S. Oxidative stress-induced DNA damage by particulate air pollution. Mutat Res. 2005; 592(1-2):119-137. [PubMed: 16085126]

50. Kawanishi S, Oikawa S. Mechanism of telomere shortening by oxidative stress. Ann N Y Acad Sci. 2004; 1019:278-284. [PubMed: 15247029]

51. Geiser M, Rothen-Rutishauser B, Kapp N, et al. Ultrafine particles cross cellular membranes by nonphagocytic mechanisms in lungs and in cultured cells. Environ Health Perspect. 2005; 113(11): 1555-1560. [PubMed: 16263511]

52. Ferin J. Pulmonary retention and clearance of particles. Toxicol Lett. 1994; 72(1-3):121-125. [PubMed: 8202922]

53. Oberdörster G, Sharp Z, Atudorei V, et al. Translocation of inhaled ultrafine particles to the brain. Inhal Toxicol. 2004; 16(6-7):437-445. [PubMed: 15204759]

54. Huang JP, Hsieh PC, Chen CY, et al. Nanoparticles can cross mouse placenta and induce trophoblast apoptosis. Placenta. 2015; 36(12):1433-1441. [PubMed: 26526105]

55. Wick P, Malek A, Manser P, et al. Barrier capacity of human placenta for nanosized materials. Environ Health Perspect. 2010; 118(3):432-436. [PubMed: 20064770]

56. Saenen ND, Vrijens K, Janssen BG, et al. Placental nitrosative stress and exposure to ambient air pollution during gestation: a population study. Am J Epidemiol. 2016; 184(6):442-449. [PubMed: 27601048]

57. Grevendonk L, Janssen BG, Vanpoucke C, et al. Mitochondrial oxidative DNA damage and exposure to particulate air pollution in mother-newborn pairs. Environ Health. 2016; 15:10. [PubMed: 26792633]

58. Proietti E, Röösli M, Frey U, Latzin P. Air pollution during pregnancy and neonatal outcome: a review. J Aerosol Med Pulm Drug Deliv. 2013; 26(1):9-23. [PubMed: 22856675]

59. Hodes RJ, Hathcock KS, Weng NP. Telomeres in T and B cells. Nat Rev Immunol. 2002; 2(9): 699-706. [PubMed: 12209138]

60. Weng NP, Levine BL, June CH, Hodes RJ. Human naive and memory T lymphocytes differ in telomeric length and replicative potential. Proc Natl Acad Sci USA. 1995; 92(24):11091-11094. [PubMed: 7479943]

61. Saenen ND, Bové H, Steuwe C, et al. Children's Urinary Environmental Carbon Load: A Novel Marker Reflecting Residential Ambient Air Pollution Exposure? Am J Respir Crit Care Med. 2017; [published online July 7, 2017]. doi: 10.1164/rccm.201704-0797OC 


\section{Key Points}

\section{Question}

Is telomere length at birth (a marker of biological aging) influenced by exposure to particulate matter air pollution during in utero life?

\section{Findings}

In this birth cohort study of 641 mother-newborn pairs, mothers with higher residential exposure to $\mathrm{PM}_{2.5}$ (particulate matter with an aerodynamic diameter $\_.5 \mu \mathrm{m}$ air pollution) gave birth to newborns with significantly lower telomere length that could not be explained by other factors including socioeconomic class. For a $5-\mu \mathrm{g} / \mathrm{m}^{3}$ increase in residential $\mathrm{PM}_{2.5}$ exposure during pregnancy, cord blood telomeres were $9 \%$ shorter and placental telomeres $13 \%$ shorter.

\section{Meaning}

Improved air quality may promote molecular longevity from birth onward. 


\section{A Cord blood}

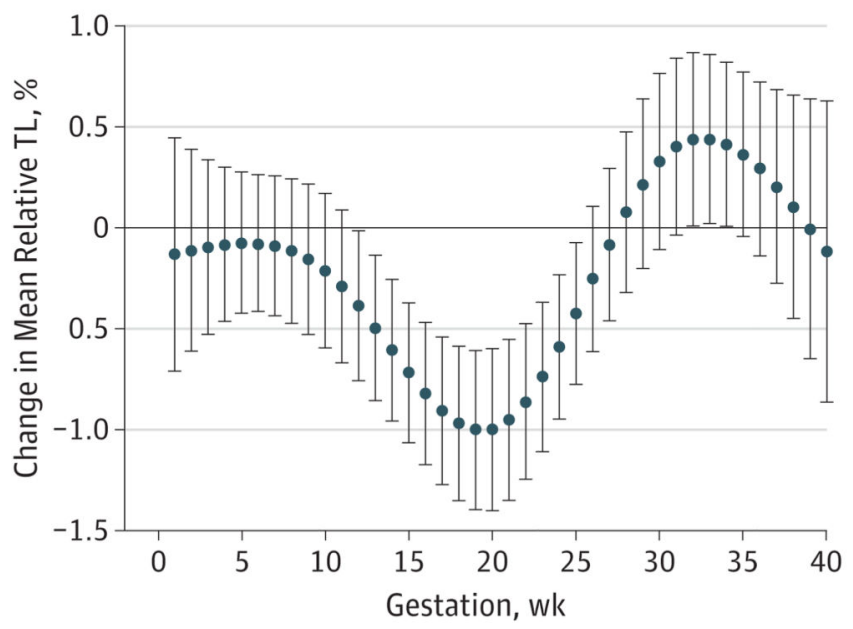

B Placental tissue

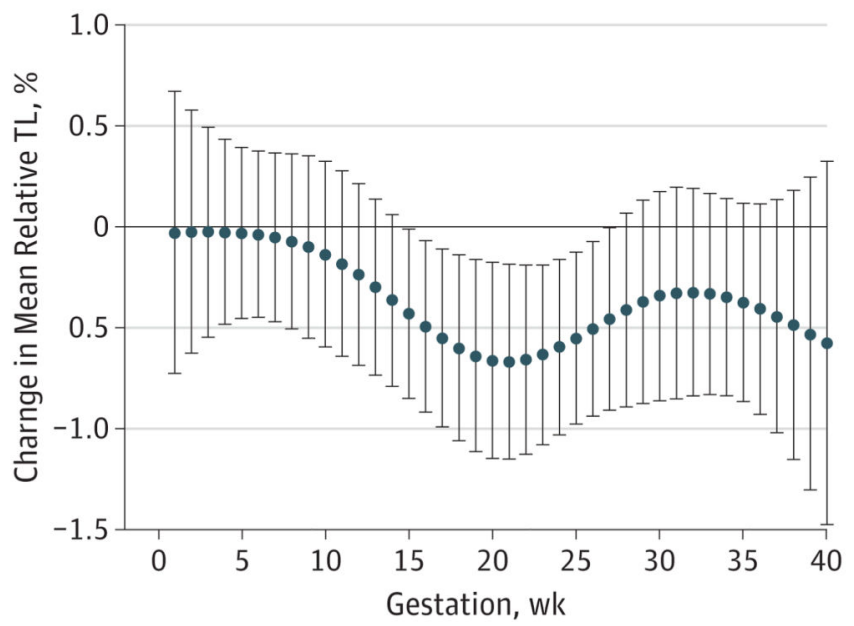

Figure. Cord Blood and Placental Telomere Length (TL) in Association With Week-Specific Prenatal PM 2.5. Exposure During Pregnancy

Week-specific estimates provided as a percentage change in mean relative TL (with 95\% CI) for a $5-\mu \mathrm{g} / \mathrm{m}^{3}$ increment of $\mathrm{PM}_{2.5}$ air pollution exposure. Models were adjusted for date of delivery, gestational age, maternal body mass index, maternal age, paternal age, newborn sex, newborn ethnicity, season of delivery, parity, maternal smoking status, maternal educational level, pregnancy complications, and ambient temperature. $\mathrm{PM}_{2.5}$ indicates particulate matter with an aerodynamic diameter of $2.5 \mu \mathrm{m}$ or less. 
Table 1

\section{Characteristics of 641 Mother-Newborn Pairs}

\begin{tabular}{|c|c|}
\hline Characteristic & No. $(\%)$ \\
\hline \multicolumn{2}{|l|}{ Newborns } \\
\hline Birth weight, mean (SD), g & $3451(428)$ \\
\hline Females & $318(49.6)$ \\
\hline White European & $567(88.5)$ \\
\hline \multicolumn{2}{|l|}{ Gestational age, wk } \\
\hline 37 & $33(5.1)$ \\
\hline 38 & $87(13.6)$ \\
\hline 39 & $196(30.6)$ \\
\hline 40 & $242(37.8)$ \\
\hline 41 & $83(12.9)$ \\
\hline \multicolumn{2}{|l|}{ Season of birth } \\
\hline Winter & $163(25.4)$ \\
\hline Spring & $140(21.8)$ \\
\hline Summer & $153(23.9)$ \\
\hline Autumn & $185(28.9)$ \\
\hline \multicolumn{2}{|l|}{ Apgar score 5 min after birth } \\
\hline 7 & $11(1.7)$ \\
\hline 8 & $45(7.0)$ \\
\hline 9 & $187(29.2)$ \\
\hline 10 & $398(62.1)$ \\
\hline \multicolumn{2}{|l|}{ Mothers } \\
\hline Age, mean (SD), y & $29.1(4.6)$ \\
\hline BMI, mean (SD) & $24.3(4.5)$ \\
\hline \multicolumn{2}{|l|}{ Educational level $^{a}$} \\
\hline Low & $71(11.1)$ \\
\hline Middle & $245(38.2)$ \\
\hline High & $325(50.7)$ \\
\hline \multicolumn{2}{|l|}{ Smoking status $b$} \\
\hline Never smoker & $401(62.6)$ \\
\hline Former smoker & $159(24.8)$ \\
\hline Current smoker & $81(12.6)$ \\
\hline Pregnancy complications $c$ & $73(11.4)$ \\
\hline Cesarean delivery & $24(3.7)$ \\
\hline \multicolumn{2}{|l|}{ Parity } \\
\hline 1 & $351(54.8)$ \\
\hline 2 & $224(34.9)$ \\
\hline
\end{tabular}




\begin{tabular}{ll}
\hline Characteristic & No. $(\%)$ \\
\hline \multicolumn{1}{c}{$(\%$} & $66(10.3)$ \\
\hline Weekly mean $\mathrm{PM}_{2.5}$ exposure, $\mu \mathrm{g} / \mathrm{m}^{3 d}$ & $13.4(4.3$ to 32.5$)$ \\
\hline Weekly mean temperature, ${ }^{\circ} \mathrm{C}^{d}$ & $10.7(-0.2$ to 19.4$)$ \\
\hline Fathers & \\
\hline Age, mean (SD), y & $31.7(5.3)$ \\
\hline
\end{tabular}

Abbreviations: BMI, body mass index (calculated as weight in kilograms divided by height in meters squared); $\mathrm{PM}_{2.5}$, particulate matter with an aerodynamic diameter of $2.5 \mu \mathrm{m}$ or less.

a Maternal educational level was coded "low" when mothers did not obtain any diploma, "middle" when they obtained a high school diploma, and "high" when they obtained a college or university degree.

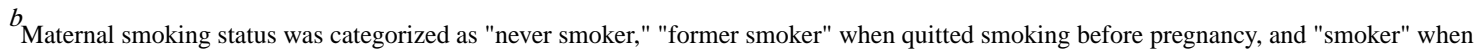
smoking continued during pregnancy.

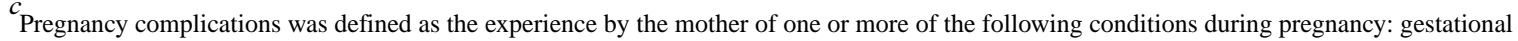
diabetes, hypertension, infectious disease, pre-eclampsia, vaginal bleeding, and hyperthyroidism or hypothyroidism.

$d$ Presented as mean (5th to 95 th percentile) and for the actual pregnancy duration. 
Table 2

\section{Association Between Newborn Telomere Length and Prenatal PM P.5 $_{\text {Exposure }}{ }^{a}$}

\begin{tabular}{lll}
\hline & \multicolumn{1}{l}{ Percentage Change (95\% CI) } \\
\cline { 2 - 3 } Exposure Window & Distributed Lag Model & Average Exposure Model \\
\hline Cord Blood (n = 641) & & \\
\hline Overall (1-40 wk) $b$ & $-8.8(-14.1$ to -3.1$)$ & $-8.4(-13.5$ to -2.9$)$ \\
\hline Trimester 1 & $-2.3(-6.1$ to 1.7$)$ & $-0.8(-4.7$ to 3.2$)$ \\
\hline Trimester 2 & $-9.4(-13.1$ to -5.6$)$ & $-9.8(-13.3$ to -6.2$)$ \\
\hline Trimester 3 & $3.1(-1.8$ to 8.3$)$ & $2.6(-1.4$ to 6.8$)$ \\
\hline Placental Tissue (n $=\mathbf{6 4 1})$ & $-12.5(-18.4$ to -6.2$)$ \\
\hline Overall (1-40 wk) $b$ & $-13.2(-19.3$ to -6.7$)$ & $-0.8(-5.5$ to 4.1$)$ \\
\hline Trimester 1 & $-1.4(-6.0$ to 3.5$)$ & $-7.4(-11.7$ to -2.9$)$ \\
\hline Trimester 2 & $-7.1(-11.6$ to -2.4$)$ & $-4.5(-9.0$ to 0.2$)$ \\
\hline Trimester 3 & $-5.3(-10.8$ to 0.5$)$ & \\
\hline
\end{tabular}

Abbreviations: BMI, body mass index; $\mathrm{PM}_{2.5}$, particulate matter with an aerodynamic diameter of $2.5 \mu \mathrm{m}$ or less.

a Estimates provided as a percentage change in mean relative telomere length for a $5-\mu \mathrm{g} / \mathrm{m}^{3}$ increment in PM 2.5 , estimated by distributed lag models using weekly mean exposures, and by mean $\mathrm{PM}_{2.5}$ during specific exposure windows (average exposure model).

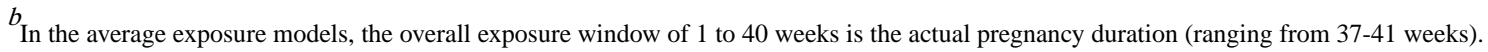
Models were adjusted for date of delivery, gestational age, maternal BMI, maternal age, paternal age, newborn sex, newborn ethnicity, season of delivery, parity, maternal smoking status, maternal educational level, pregnancy complications, and ambient temperature. 


\section{Table 3}

\section{Sensitivity Analyses $^{a}$}

\begin{tabular}{|c|c|c|c|}
\hline \multirow[b]{2}{*}{ Model } & \multirow[b]{2}{*}{ No. } & \multicolumn{2}{|l|}{ Percentage Change (95\% CI) } \\
\hline & & Cord Blood Telomere Length & Placental Telomere Length \\
\hline Main model & 641 & $-8.8(-14.1$ to -3.1$)$ & $-13.2(-19.3$ to -6.7$)$ \\
\hline Unconstrained lag structure & 641 & $-8.4(-14.0$ to -2.5$)$ & $-14.0(-20.2$ to -7.3$)$ \\
\hline Additional adjustment for month of delivery & 641 & $-9.2(-14.6$ to -3.4$)$ & $-12.3(-18.6$ to -5.6$)$ \\
\hline Excluding non-European mothers & 567 & $-8.7(-14.4$ to -2.6$)$ & $-11.9(-18.6$ to -4.8$)$ \\
\hline Excluding mothers with low educational level & 570 & $-10.0(-15.4$ to -4.1$)$ & $-13.4(-19.8$ to -6.4$)$ \\
\hline Excluding current and former smokers & 401 & $-12.1(-18.8$ to -4.9$)$ & $-16.2(-23.5$ to -8.2$)$ \\
\hline Excluding mothers with pregnancy complications & 568 & $-9.1(-14.7$ to -3.2$)$ & $-14.3(-20.7$ to -7.4$)$ \\
\hline Excluding cesarean deliveries & 617 & $-8.7(-14.1$ to -2.9$)$ & $-12.8(-19.0$ to -6.1$)$ \\
\hline Excluding all of the above & 281 & $-14.0(-21.9$ to -5.2$)$ & $-13.3(-22.3$ to -3.2$)$ \\
\hline
\end{tabular}

Abbreviations: BMI, body mass index; $\mathrm{PM}_{2.5}$, particulate matter with an aerodynamic diameter of $2.5 \mu \mathrm{m}$ or less.

${ }^{a}$ Estimates provided as a cumulative (weeks 1-40) percentage change in mean relative telomere length for a 5 - $\mu \mathrm{g} / \mathrm{m}^{3}$ increment in PM2.5. Models were adjusted for date of delivery, gestational age, maternal BMI, maternal age, paternal age, newborn sex, newborn ethnicity, season of delivery, parity, maternal smoking status, maternal educational level, pregnancy complications, and ambient temperature. The season of delivery was removed from the model adjusting for month of delivery. 